\title{
RESENHA DO LIVRO: EDUCAÇÃO COMO PRÁTICA DA LIBERDADE: PAULO FREIRE
}

\author{
Arthur Braga de Oliveira ${ }^{1}$ \\ André Luiz Zanella ${ }^{2}$ \\ Gustavo Braga de Oliveira ${ }^{3}$
}

O livro Educação como prática de liberdade de Paulo Freire, vem detalhar seu trabalho realizado com Adultos em seu método de ensino e alfabetização entre 1962 e 1964 , no nordeste brasileiro, antes do Golpe de 64. Este trabalho foi composto por I23 páginas e foi publicado pela editora $\mathrm{Paz}$ e Terra originalmente em 1967.

Pierre Furter faz a apresentação do livro e do autor em PAULO FREIRE ou O Poder da Palavra, onde fala da oralidade e estilo pedagógico, onde cita que a oralidade do autor revela toda sua práxis, ou seja, toda sua convicção que o homem foi criado para se comunicar com os outros, onde as palavras não sejam ôcas e nem e que ninguém seja excluído a margem da vida nacional, formando de maneira crítica, sua conscientização, democraticamente ultrapassando o pensamento de rebelião.

A introdução do livro, Educação e Política (Reflexões sociológicas sobre uma pedagogia da Liberdade) foi escrita por Francisco C. Weffort, que desataca as experiências do método na cidade de Angicos, no Rio Grande do Norte, no ano de 1962, onde 300 trabalhadores rurais foram alfabetizados em 45 dias. Nela o autor cita os trabalhos realizados entre 1963 e 1964 onde eram previstos a criação de 20.000 círculos de cultura para analfabetos. Porém, o Golpe de 64 veio interromper esse trabalho e Paulo Freire não foi compreendido e exilado (período em que escreveu a obra). Segundo Weffort, o maior

\footnotetext{
${ }^{\mathrm{I}}$ Licenciado e Bacharel em Educação Física - UNEC Mestrando em Educação Profissional Tecnológica IFTM campus Uberaba Especialista em TIC's para o Ensino Fundamental - UFJF Especialista em Atividades Motoras - UNEC Instituição de Ensino - IFTM campus Paracatu

${ }^{2}$ Licenciatura Plena em Educação Física Mestrado em Educação - UFRRJ Mestrado em Educação Física e Desportos - UTAD Especialista em treinamento Funcional - IBAESP Instituição de Ensino - Colégio Militar de Curitiba

${ }^{3}$ Licenciatura em Educação Física - UFES Bacharel em Educação Física - Claretiano Centro Universitário Especialista em Educação a Distância: Planejamento, Implantação e Gestão - Claretiano Centro Universitário Especialista em Educação Física Escolar (Centro de Estudos Avançados em Pós-graduação e Pesquisa) - UFES Instituição de Ensino: Claretiano Centro Universitário
} 
esforço já feito pela democratização da cultura foi destruído e desestruturado pelo Golpe de 64.

Em seguida, é apresentado por Thiago de Melo, a Canção Para os Fonemas da Alegria, em Santiago do Chile, no verão de 1964 e segue-se apresenta-se as partes principais do livro, que é dividido em 4 capítulos: Capítulo i: A Sociedade Brasileira em Transição Capítulo 2: Sociedade Fechada e Inexperiência Democrática Capítulo 3: Educação "Versus" Massificação Capítulo 4: Educação e Conscientização.

Assim, no capítulo I, intitulado A Sociedade Brasileira em Transição, Paulo Freire tenta fazer com que todos acreditem no homem, onde a destinação não era coisificar-se, mas sim humanizar-se. Para ele, ele existir ultrapassava o viver, porque é mais do que estar no mundo, é estar nele e com ele.

Herdando a experiência adquirida, criando e recriando, integrando-se às condições de seu contexto, respondendo a seus desafios, objetivando-se a si próprio, discernindo, transcendendo, lança-se o homem num domínio que lhe é exclusivo - o da História e o da Cultura (FREIRE, 1967 p.4I)

A sua capacidade de compreender o seu tempo, de compreender a si mesmo, de compreender os outros o seu meio e de transformar a natureza para obter seu próprio sustento é sua principal diferença para os animais.

Mas para isso, é sempre necessária uma atitude permanente crítica, onde, segundo ele, é a única maneira natural de interagir e integrar-se. Adaptando-se, criando, recriandose e decidindo é que o homem vai participando das épocas históricas.

No entanto, o que se sente, dia a dia, é o homem simples esmagado, diminuído e acomodado, convertido em espectador, aniquilados pelo poder dos mitos que forças sociais poderosas criam para ele. Um homem assustado, temendo a convivência e até duvidando da sua possibilidade, ao lado do medo da solidão, que se alonga como medo da liberdade, sem vínculo crítico e amoroso, o que o tornariam uma unidade cooperadora.

Segundo o autor, vivia-se uma passagem de uma época para outra, o que ele chamava de passagem de trânsito. Uma sociedade fechada, alienada culturalmente, elite distante do povo e sendo comandadas por ela, o que contribuía para os elevados índices de analfabetismo. Uma opressão desde a colonização, que não permite a sociedade de adquirir uma consciência crítica sobre essa opressão. Mas essa luta entre os poderes e quem estavam neles, fez com que houvesse uma rachadura e perdeu-se o equilíbrio da sociedade 
fechada e despertou um senso de atitudes optativas com tendência de radicalização na opção, entre os brasileiros.

Dessa forma é que a Educação ganha força nessa sociedade fechada. Onde o que estivesse nele, mas não fosse dele, do que, estando nele, fosse realmente dele. Desempenhando um papel social e político importante, dialogando e sendo ativa na sociedade, obtendo uma transitividade crítica pautada na interpretação dos problemas, afim de resolve-los democraticamente.

No segundo capítulo, nomeado Sociedade Fechada e Inexperiência Democrática, Paulo Freire faz uma contextualização sobre o período colonial do Brasil, mostrando que as características e a forma que ela se deu refletiram diretamente para uma consciência não crítica da população e mesmo com a chegada do período Imperial, pouca coisa havia mudado nessa forma de pensamento e maneira de aceitação da submissão deflagrada pelos senhores e elite da época, caracterizando uma inexperiência democrática por parte da grande parte da sociedade. Segundo o autor, faltou um pouco de integração com a colônia pelos colonizadores. Oscilavam entre o poder do senhor das terras, o poder do governador e do capitão-mor.

Esse capítulo, mostra uma transição da sociedade antes majoritária rural para uma sociedade um pouco mais urbana, com as pessoas migrando para os centros urbanos e indo atrás das indústrias. Porém, essa migração ainda era marcada pela ausência de diálogo entre as classes, com um "mutismo" por parte da população e esse mutismo, na maioria das vezes gerados pela submissão ao poder dos poderosos, se tornando o homem, um ser acomodado a sua submissão.

Novos centros urbanos, porém, frágeis, sem o poder do povo, sem o direito ao voto e ao ser votado, homens comuns vivendo para homens privilegiados. Mesmo com os avanços gerados com a chegada da família real ao Brasil, criação de escolas, imprensa, bibliotecas, etc., ainda era muito pouco a dialogação entre as classes, mas já foi um marco para o primeiro surto de reformas que estavam por vir.

Agora, a grande força das cidades estava na burguesia, europeizadas, onde continuávamos a nutrir nossa inexperiência democrática e política. Mas foi nesse século e devido a esse processo de urbanização que se observou os primeiros avanços. Começava-se a ter as primeiras manifestações de participação popular na sociedade com uma experiência democráticas. Segundo o autor, o país começava a encontrar-se consigo mesmo, superando 

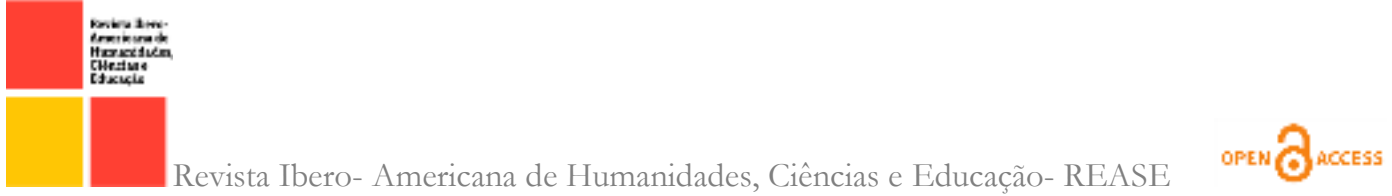

a inexperiência democrática, por uma experiência, a de participação. Essa experiência que se iniciara, da superação e do clima de irracionalidade que vivia na época o Brasil, agravado pela situação internacional.

Mais adiante, no terceiro capítulo, Educação Versus Massificação, Paulo Freire vem mostrar a importância que teria nesse processo de mudança para uma consciência mais crítica e democrática, a participação dos educadores, juntamente com os economistas, sociólogos em realizar uma educação mais crítica e criticizadora, passando da transitividade ingênua à transitividade crítica, incorporando o diálogo de um com o outro, o que era necessário para a democracia. Uma democracia com direito a voto, a ser votado e principalmente, o direito de voz, mas sem que isso despertasse na elite, uma revolta eminente, pois vinham a emersão da população como uma ameaça aos seus privilégios.

Segundo o autor, era necessária uma educação para a decisão, para a responsabilidade social e política, com uma discussão corajosa, com força e coragem pra lutar, ouvindo, perguntando e investigando, promovendo realmente uma "mudança" e desenraizando de um passado de submissão e opressão.

Era então necessária uma educação que não fosse ôca, e que deixasse de ser teórica. Freire diz que a educação vigente não é teórica porque lhe falta o gosto da comprovação, da invenção e da pesquisa, mas sim porque ela não comunica, tento ela a função não só de combater o analfabetismo, mas também de superação da inexperiência democrática.

Segundo o autor, nada na educação vigente fazia com que o aluno se motivasse a buscar algo novo, nada que desenvolvesse o gosto pela pesquisa, pela resolução de problemas e é exatamente isso, segundo ele, que implicaria no desenvolvimento da consciência transitivo-crítica. A escola com seus métodos de memorização, desvinculação da realidade e com tendência e reduzir os meios de aprendizagem, a caracterizavam como muito ingênua. Quanto menos criticidade nos seres humanos, mais ingenuamente tratarão os problemas e tentarão resolvê-los.

Apenas de um período pra cá é que se começou a se preocupar em fazer-se identificados com a realidade. É o clima de transição. E foi a partir desse clima que se começou a trabalhar em cima da crença de que o homem pode e deve, através de educação, discutir sua realidade, seus problemas, seus anseios, os problemas do País, do mundo e do seu trabalho de forma democrática. Essa educação pautada em todos os graus de 
conhecimento com uma visão mais humanista, formando educandos e professores sem alienação e medo de expor seus objetivos, anseios, e pensamento democrático.

Por fim, o quarto e último capítulo do livro, Educação e Conscientização, Paulo Freire nos mostra seu método de ensino para adultos, contando suas experiências, os problemas encontrados, o golpe de 64 e o fim da aplicação do método.

O Movimento de Cultura Popular do Recife, através do projeto de Educação para Adultos, era essa base de educação pautada por Paulo Freire e foi uma experiência importantíssima. Nelas eram criadas situações de debates ao grupo na tentativa de buscar aclaramento de ações e situações. Esses assuntos eram esquematizados, em um primeiro momento do método, e, com ajudas visuais, apresentados aos grupos, em forma dialogal. Assim, era afastado qualquer método de educação mecanicista, buscando a promoção da ingenuidade em criticidade, ao mesmo tempo em que eram alfabetizados.

Era uma educação direta, ligada a criticidade e democracia da cultura.

Pensávamos numa alfabetização que fosse em si um ato de criação, capaz de
desencadear outros atos criadores. Numa alfabetização em que o homem, porque
não fosse seu paciente, seu objeto, desenvolvesse a impaciência, a vivacidade,
característica dos estados de procura, de invenção e reivindicação (Freire, 1967. p.
I04)

Paulo Freire passou a buscar sempre uma educação dialogal, mostrando a importância da cultura, pautadas no debate crítico, construtivo, sem cartilhas previamente elaboradas.

O segundo momento da metodologia era caracterizado pela escolha das palavras, selecionadas do universo vocabular pesquisado. O terceiro momento consiste na criação de situações existenciais típicas do grupo com quem se vai trabalhar. Já a quarta fase, era composta pela elaboração de fichas roteiro, que auxiliam os coordenadores de debate no seu trabalho. Estas fichas-roteiro eram meros subsídios para os coordenadores e não uma cartilha rígida a ser seguida. Assim, finalizava com a quinta fase, que era a feitura de fichas com a decomposição das famílias fonêmicas correspondentes aos vocábulos geradores.

Porém, o método não foi concluído e mais de 20 mil Círculos de cultura deixaram de serem feitor em 1964. Acusações de todos os lados, sem fundamentos ao método, a Paulo Freire e sua pedagogia. Findaram o programa, e instalaram uma educação tecnicista voltada ao trabalho de internacionalização brasileira, interrompendo, por um instante, o sonho de algumas pessoas e a transição do estado brasileiro. O que nos amargurava não era 
outra coisa senão a ameaça dos irracionalismos à nossa destinação democrática, anunciada na transição brasileira (FREIRE, 1967· p. I2I).

É uma obra esclarecedora e ao mesmo tempo complexa, mas através dessas primeiras lutas por uma educação democrática, crítica, libertadora é que se iniciou mais a frente a luta por uma pedagogia diferente, mais inovadora, mas que ainda solidária. Fica claro a necessidade de dar continuidade ao projeto de Freire, resgatando conceitos, atitudes, pedagogias e um pensar mais crítico dos educandos e dos educadores, quebrando um pouco essa pedagogia tradicional vigente, que na grande maioria, é engessada, pragmática e pouco exploratória.

A obra também nos deixa claro que não é difícil mudarmos nossa maneira de trabalhar, de pensar a educação para nossos alunos. Mas para isso é preciso se mexer, sair do comodismo e colocar em prática os conhecimento e metodologias libertadores existentes, e quem sabe, se iniciar uma nova metodologia inexplorada.

FREIRE, Paulo. Educação como Prática da Liberdade. Rio de Janeiro: Paz e Terra, 1967. 